Article

\title{
Structure and Mechanical Properties of HVOF Sprayed (WC-Co+Co) Composite Coating on Ductile Cast Iron
}

\author{
Marzanna Ksiazek 1, ", Lukasz Boron ${ }^{2}$, Adam Tchorz ${ }^{2}$, Ryszard Grzelka ${ }^{3}$ \\ ${ }^{1}$ AGH University of Science and Technology, Department of Non-Ferrous Metals, Poland; \\ 2 Foundry Research Institute, Poland; \\ mgr inż. Boron Lukasz; lukasz.boron@iod.krakow.pl \\ mgr inż. Tchorz Adam; adam.tchorz@iod.krakow.pl \\ ${ }_{3}^{3}$ Plasma System S.A., Poland, mgr inż. Grzelka Ryszard; grzelka.ryszard@plasmasystem.pl \\ * Correspondence: dr hab. inż. Ksiazek Marzanna; mksiazek@agh.edu.pl
}

Received: 02.02.2019; Accepted: 07.03.2019

\begin{abstract}
An investigation was conducted to determine the role of Co particles in the WC-Co coating produced with the High Velocity Oxygen-Fuel (HVOF) spraying on microstructure, mechanical and wear properties in a system of type: WC-Co coating/ductlile cast iron. The microstructure of the thermal sprayed WC-Co+Co coating was characterized by scanning electron (SEM) and transmission electron (TEM) microscopes as well as the analysis of chemical and phase composition in microareas (EDS, XRD). For analysis of the quality and adhesion of coatings, the scratch-test was applied. It was found that as a result of the HVOF spray of WC-Co powders with the addition of Co particles, the coatings of low porosity, high hardness, a very good adhesion to the substrate, compact structure with partially molten Co particles and finely fragmented WC particles embedded in a cobalt matrix, coming to the size of nanocrystalline sizes were obtained. Moreover, the results were discussed in reference to examination of bending strength considering cracking and delamination in the system of $(\mathrm{WC}-\mathrm{Co}+\mathrm{Co}) /$ ductile cast iron as well as hardness and wear resistance of the coating. It was found that the addition of Co particles was significantly increase resistance to cracking and wear behaviour in the studied system.
\end{abstract}

Keywords: thermal spraying; HVOF; WC-Co coating; wear resistant

\section{Introduction}

A coating material constituting the subject of multiple research works is hard tungsten carbide in the cobalt matrix characterised by high resistance to wear [1]. WC-Co coatings are widely used in order to: (i) increase the durability of various machine and equipment components, such as: dies for extrusion and hot forming, dies, forging tools, gas turbine nozzles, sleeves, printing rollers, piston rings and many others, (ii) reduction of production costs, (iii) material and energy savings, as well as (iv) regeneration of the above-mentioned components. Supersonic processes are most often used when applying WC-Co coatings by means of thermal spraying methods. Plasma spraying was previously used, yet the interaction of high plasma temperature and the presence of oxygen caused phase changes during the flight of particles of the coating material, i.e. decomposition of carbide and decarburisation, leading to the formation of brittle phases of $\mathrm{W}_{2} \mathrm{C}, \mathrm{W}$ and $\mathrm{Co}_{\mathrm{x}} \mathrm{W}_{\mathrm{y}} \mathrm{C}$ 作 type as well as oxidation of the coating, which consequently led to deterioration of the coating's performance properties [2]. The use of supersonic spray (HVOF) reduced these adverse effects due to the higher velocities and lower temperatures experienced by the powder particles. Consequently, this results in higher quality, more wear-resistant coatings, with higher levels of retained WC and less porosity [3:5]. The aim of the work was to assess the effect of modifying the chemical composition by doping of standard WC-12Co powders with metallic Co particles during consolidation of coatings on ductile cast iron in the process of High Velocity Oxygen Fuel (HVOF) on the structure, mechanical and wear properties of a composite coating system ( $\mathrm{WC}-\mathrm{Co}+\mathrm{Co}) /$ ductile cast iron in combination with the analysis of cracking and delamination of the coating in the area of the interface. 


\section{Test methodology}

The composite coating was produced by supersonic powder spraying of carbide powder with WC-12Co composition ( $88 \%$ WC- $12 \%$ Co) with a grain size of $-45+15 \mu \mathrm{m}$, into which $10 \mathrm{wt}$. $\%$ of $20 \mu \mathrm{m}$ Co particles were introduced. In order to spray the coatings, a HV50 HVOF System in the company Plasma System S.A. was used, where a mixture of kerosene and oxygen was used as the fuel for the spraying process. The substrate made of ductile cast iron EN-GJS-500-7 with the following chemical composition is given in Table I, was characterised by the following mechanical properties are given in Table II.

Table I. Chemical composition of EN-GSJ-500-7

\begin{tabular}{cccccccccc}
\hline & \multicolumn{1}{c}{ Chemical composition, wt.\% } \\
$\mathbf{C}$ & $\mathbf{S i}$ & $\mathbf{M n}$ & $\mathbf{P}$ & $\mathbf{S}$ & $\mathbf{C r}$ & $\mathbf{N i}$ & $\mathbf{M g}$ & $\mathbf{C u}$ & $\mathbf{F e}$ \\
\hline 3.61 & 2.29 & 0.45 & 0.045 & 0.009 & 0.03 & 0.01 & 0.057 & 0.75 & rest \\
\hline
\end{tabular}

Table II. Mechanical properties of EN-GSJ-500-7

\begin{tabular}{cccc}
\hline Tensile strength, $\mathrm{MPa}$ & Conventional yield point, $\mathrm{MPa}$ & Elongation, $\%$ & Hardness, HB \\
\hline 500 & 340 & 7 & 220 \\
\hline
\end{tabular}

The substrate samples had the dimensions of $100 \times 15 \times 5 \mathrm{~mm}$. Prior to spraying, the surface of the substrates was sandblasted with loose corundum of 20 mesh granulation. The parameter of the substrate surface roughness Ra amounted to $30 \mu \mathrm{m}$. The technological parameters of the spraying process are given in Table III. The average thickness of the applied coating was $200 \mu \mathrm{m}$.

Table III. HVOF spraying parameters

\begin{tabular}{cccccc}
\hline $\begin{array}{c}\text { Gun } \\
\text { movement } \\
\text { speed, } \mathbf{~ m m / s}\end{array}$ & $\begin{array}{c}\text { Oxygen, } \\
\mathbf{1 / m i n}\end{array}$ & Kerosene, $\mathbf{l} / \mathbf{h}$ & $\begin{array}{c}\text { Powder feed rate } \\
\mathbf{g} / \mathbf{m i n}\end{array}$ & $\begin{array}{c}\text { Powder feed gas, } \\
\mathbf{1 / \mathbf { m i n }}\end{array}$ & Spray distance, $\mathbf{m m}$ \\
\hline 583 & 944 & 25.5 & 92 & nitrogen, 9.5 & 370 \\
\hline
\end{tabular}

A light microscope (LM), a scanning electron microscope (SEM, Dual Beam Scios FEI) and a transmission electron microscope (TEM, JOEL 2010 ARD) equipped with EDS spectrometers were used to study the structure and chemical composition of the coating/substrate type system. Coating/substrate type preparations for the transmission microscope in the form of a thin foil were obtained thanks to the use of ion thinning in a special device Gatan PIPS691V3.1 for low-angle thinning [6]. The phase composition was determined by means of X-ray phase analysis on X'Pert Pro Panalytical diffractometer in the $20 \div 90^{\circ}$ angular range with $\mathrm{CuK}$ radiation. The measurement of the carbide coating porosity was carried out on microscopic photographs (LM) using Aphelion 3.0 programme to analyse the stereological parameters of the microstructure. The measurements of microhardness of the coatings were carried out on metallographic samples made on cross-sections of normal samples to their surface by means of the Vickers method using Hanemann microhardness meter, mounted on Neophot 2 microscope at a load of $0.1 \mathrm{kG}$. The measurements of the indentation hardness were carried out for the precise assessment of the microhardness of the coatings. Measurements of indentation hardness (Нгт) and Young's modulus (Егт) were carried out using a multifunction measuring platform equipped with a microhardness meter by Anton Paar. In this method, it is possible to evaluate the process of pressing an indenter into a material by measuring both force and displacement during plastic and elastic deformation. By registering the entire application and removal force cycle, hardness values equivalent to traditional hardness values as well as other material properties such as the pressing module can be determined. The advantage of this method is that all of the mentioned values can be calculated without having to measure the size of the imprint of an indenter. The hardness measurement with this method was carried out for a load force of $1 \mathrm{~N}$ and a load speed of $2 \mathrm{~N} / \mathrm{min}$. Five measurements were carried out for each sample. As part of the experiment, measurements of the surface roughness of coatings made by means of plasma spray using a confocal microscope were carried out. Three-dimensional 
images and their analysis allowed for a precise understanding of the geometrical structure of the examined surfaces.

The strength of the coating/substrate connection was determined during a 3-point bending test on INSTRON $8800 \mathrm{M}$ strength machine using a specially designed holder for coating/substrate type samples with dimensions of $100 \times 15 \times 5 \mathrm{~mm}$. The spacing of supports amounted to $70 \mathrm{~mm}$, while the deformation rate was $1 \mathrm{~mm} / \mathrm{min}$. Three samples were used for a single test. Observations of the surface of fractures after a 3point bending test were carried out using a scanning microscope.

Tests of adhesion of coatings to the substrate and determination of other mechanical types of damage were carried out using a scratch test using a Rockwell penetrator. The test was carried out on a multifunction measuring platform (Micro-Combi Tester, Switzerland) equipped with Anton Paar scratch test heads according to the standard [7]. The scratch length amounted $5 \mathrm{~mm}$. The tests were carried out using a Rockwell $\mathrm{C}$ diamond with a rounding radius of $50 \mu \mathrm{m}$ with a linear increase in normal force, loading this penetrator in the $1 \div 20 \mathrm{~N}$ range. The indenter's shift rate was $5 \mathrm{~mm} / \mathrm{min}$. The parameters measured during the test were the penetration depth of the indenter $P_{d}$, the force acting on the indenter $F_{N}$ and the acoustic emission signal Ae. Damage to the coating/substrate system is detected and evaluated on the basis of direct microscopic observation of the crack formed and by measuring the acoustic emission. The normal force at which damage occurs is called the critical load Lc. A critical load was determined, causing cohesive ( $\left.\mathrm{Lc}_{\mathrm{c}}\right)$ and adhesive ( $\mathrm{Lc}_{\mathrm{c}}$ ) cracks determining the quality of the coating and substrate bonding.

\section{Test results and discussion}

Figure 1 presents the results of metallographic observations of composite coatings (WC-Co)+Co sprayed on a ductile cast iron substrate. The coatings produced were characterised by the structure typical of thermal spraying, i.e., layered flattened grains formed by powder particles, which undergo severe plastic deformation and geometric changes in the HVOF process [5,8]. In the structure of coatings, fine tungsten carbide particles of various sizes embedded in a cobalt matrix, partially melted Co particles (which, after striking against the substrate, change their shape from spherical to elongated, decrease their height and extend parallel to the surface of the substrate) and pores occur. Co particles introduced into the coating material, constituting a soft phase compared to the brittle tungsten carbide grains, are more susceptible to plastic deformation and are responsible for the plasticity of the carbide coatings. The coating is characterised by a compact structure without cracks or micro-voids and good adhesion to the substrate (the interface between the substrate and the coating is continuous), which indicates favourable conditions of the application process, ensuring adequate adhesion of the coating to the substrate. The reduction of porosity and increase of the surface smoothness in the composite coating WC-Co+Co was found in relation to the coating without Co particles. The porosity of the composite coating is $2.5 \%$, and the value of the surface roughness parameter Ra is $3.7 \mu \mathrm{m}$. For the WC-Co coating without Co particles, the porosity and value of the parameter Ra are $4.0 \%$ and $5.5 \mu \mathrm{m}$ respectively. The addition of Co has a positive effect on reducing the porosity of the coating, as Co particles have a much lower melting point compared to WC particles and fill the pores in the coating more easily. In order to present the differences in the chemical composition of the composite coating (WC-Co+Co) in detail, a surface, linear and point analysis of the chemical composition were carried out using SEM-EDS microanalysis (Fig. 2). In the coatings, areas can be distinguished in which not only a significant proportion of tungsten or cobalt occurs, but also varying degrees of remelting (areas with Co particles characterised by a dendritic structure). Light grains in the composite coating $(\mathrm{WC}-\mathrm{Co}+\mathrm{Co})$ constitute a phase with a high content of tungsten, while the darker ones are the areas of the occurrence of the metallic phase - Co. In order to present the differences in the chemical composition of the composite coating (WC-Co+Co) in detail, a surface, linear and point analysis of the chemical composition were carried out using SEM-EDS microanalysis (Fig. 2). In the coatings, areas can be distinguished in which not only a significant proportion of tungsten or cobalt occurs, but also varying degrees of remelting (areas with Co particles characterised by a dendritic structure). Light grains in the composite coating ( $\mathrm{WC}-\mathrm{Co}+\mathrm{Co}$ ) constitute a phase with a high content of tungsten, while the darker ones are the areas of the occurrence of the metallic phase - Co. Microscopic observations indicate a strong fragmentation of tungsten carbide grains, on average from approx. $40 \mu \mathrm{m}$ in the initial state to approx. $0.5 \div 2 \mu \mathrm{m}$ in both the coating and in the area of coating/substrate interface. No penetrateon (diffusion) of elements from the substrate material to the coating and vice versa was found, which in consequence indicates the adhesive mechanism of bonding between the coating material and substrate and no changes in the cast iron microstructure after the spraying process (ferrite and perlite constitute the matrix of cast iron both before and after spraying). 

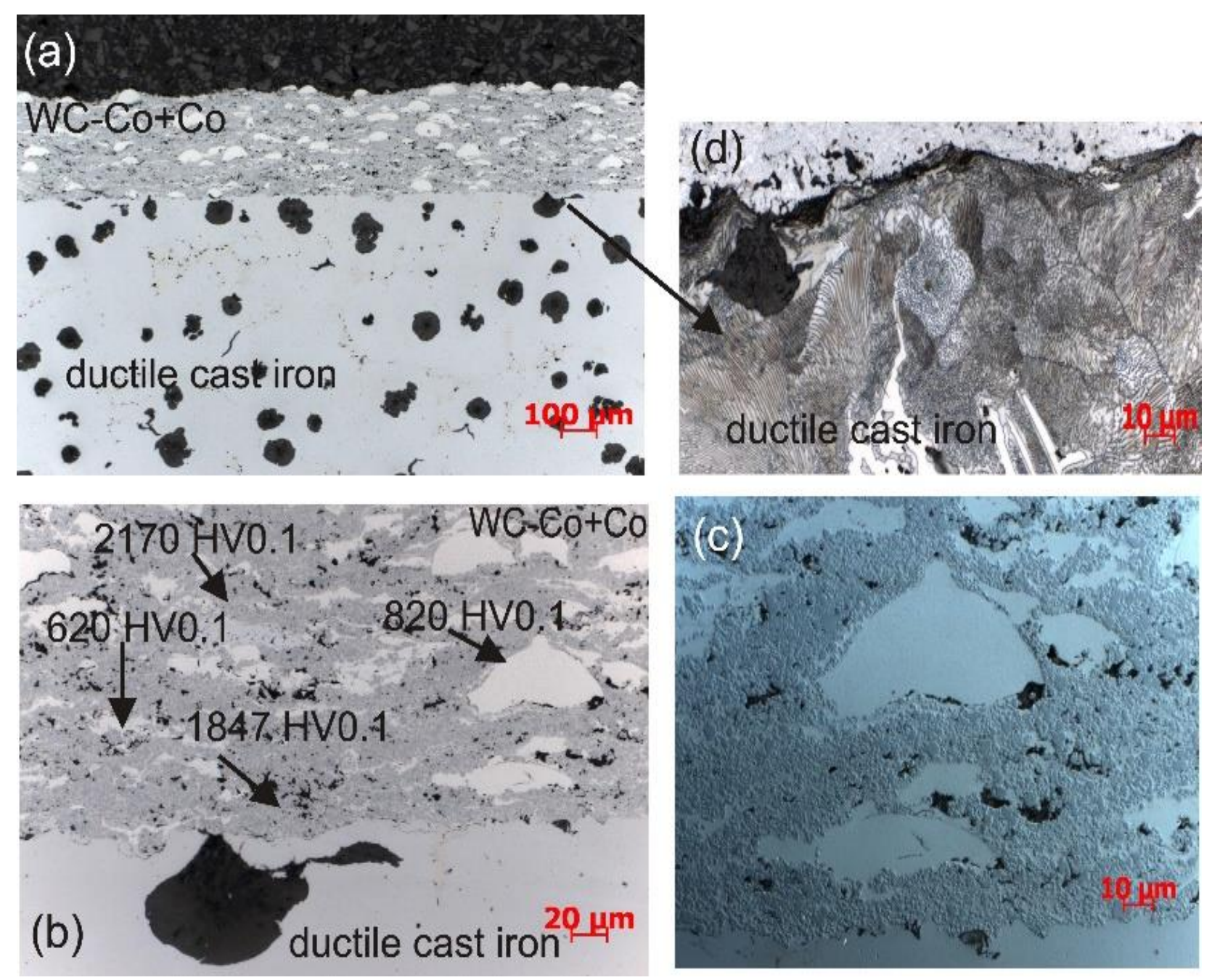

Fig. 1. a) Microstructure of the composite coating (WC-Co+Co) deposited on ductile cast iron LM, b) magnified area selected in Fig. 1a, c) details of the coating structure in differential interference contrast (DIC), and d) cast iron structure composed of ferrite and perlite

Measurements of microhardness of coatings show significant dispersion, which is associated with their structure. In areas containing tungsten carbides, the hardness ranges from 1847 to 2170 HV0.1, while in the area of partially melted Co particles, the hardness varies from 620 to 820 HV01. Doping with metallic particles resulted in local reduction in the hardness of the coating, which consequently reduces its brittleness. It is worth noting here that after spraying the composite coating on ductile cast iron, a 8.5-fold increase in ductile iron hardness is observed compared to the initial state, i.e. without the coating (metal matrix hardness equals 230 HV0.1). The results of indentation measurements, i.e. hardness Нгт and Young's modulus Eгт of the tested coatings, are from 14.17 to $15.58 \mathrm{GPa}$ and 301.28 to 301.88 GPa respectively for the areas of WC occurrence. On the other hand, for areas of the occurrence of Co particles, the values of hardness and Young's modulus are from 6.58 to $9.99 \mathrm{GPa}$ and from 162.43 to $256.12 \mathrm{GPa}$ respectively. Figure 3 shows the change of force during loading and unloading, enabling the determination of the hardness and the Young's modulus in the specific area of the coating. X-ray analysis of the phase composition revealed the occurrence of carbide phases: $W C$ and $W_{2} C$, a small proportion of $W$ and a significant proportion of $\mathrm{Co}$ (Fig. 5). The new phases of $\mathrm{W}_{2} \mathrm{C}$ and $\mathrm{W}$ are fragile and are the result of the decomposition of $\mathrm{WC} \rightarrow \mathrm{W}_{2} \mathrm{C}+\mathrm{C}$ and $\mathrm{W}_{2} \mathrm{C} \rightarrow 2 \mathrm{~W}+\mathrm{C}$ carbides as a result of the spray jet acting on the WC powder grains [9]. Due to the fact that Co particles have a lower Young's modulus, which means that the composite coating has a lower modulus value compared to the WCCo coating. Thus, the presence of Co particles as a plasticising phase improves the coating's resistance to cracking. Detailed microstructural tests of the coating carried out on a thin TEM foil from the cross-section of the sample showed a nanocrystalline structure with a band-like character. In the coating microstructure there are longitudinal bands with a thickness of $100 \div 300 \mathrm{~nm}$ arranged parallel to each other (Fig. 4) inside which nanocrystalline grains (from $10 \div 30 \mathrm{~nm}$ ) of well-defined and regular shapes occur. 


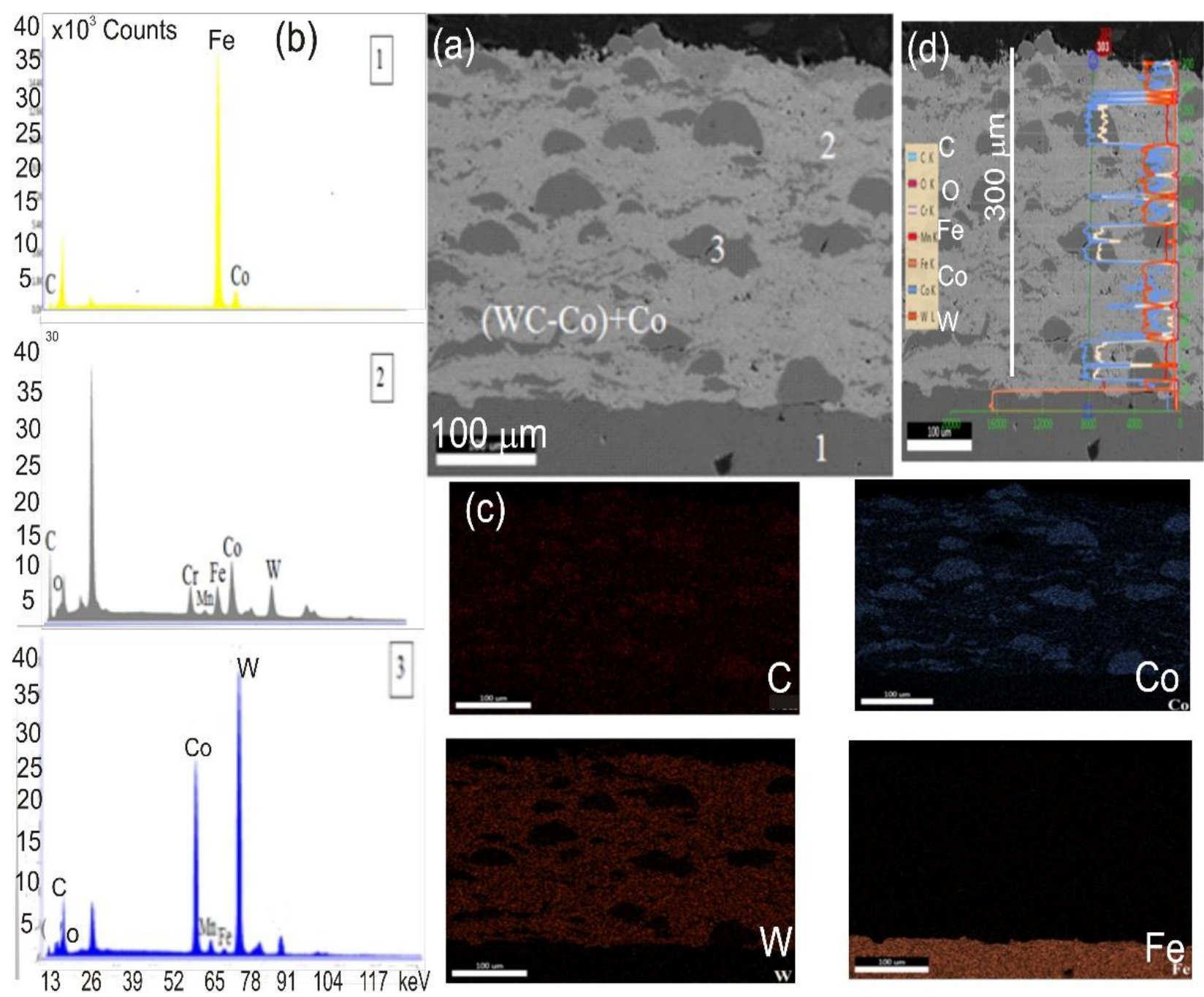

Fig. 2. a) Scanning micrographs of the composite coating (WC-Co+Co) deposited on ductile cast iron interface with

b) EDS spectra taken from the marked points:1, 2 and 3, c) map of distribution of concentrations of C, W, Co, Fe taken from the region of interface, d) linear distribution of $\mathrm{C}, \mathrm{O}, \mathrm{W}, \mathrm{Co}$ and $\mathrm{Fe}$

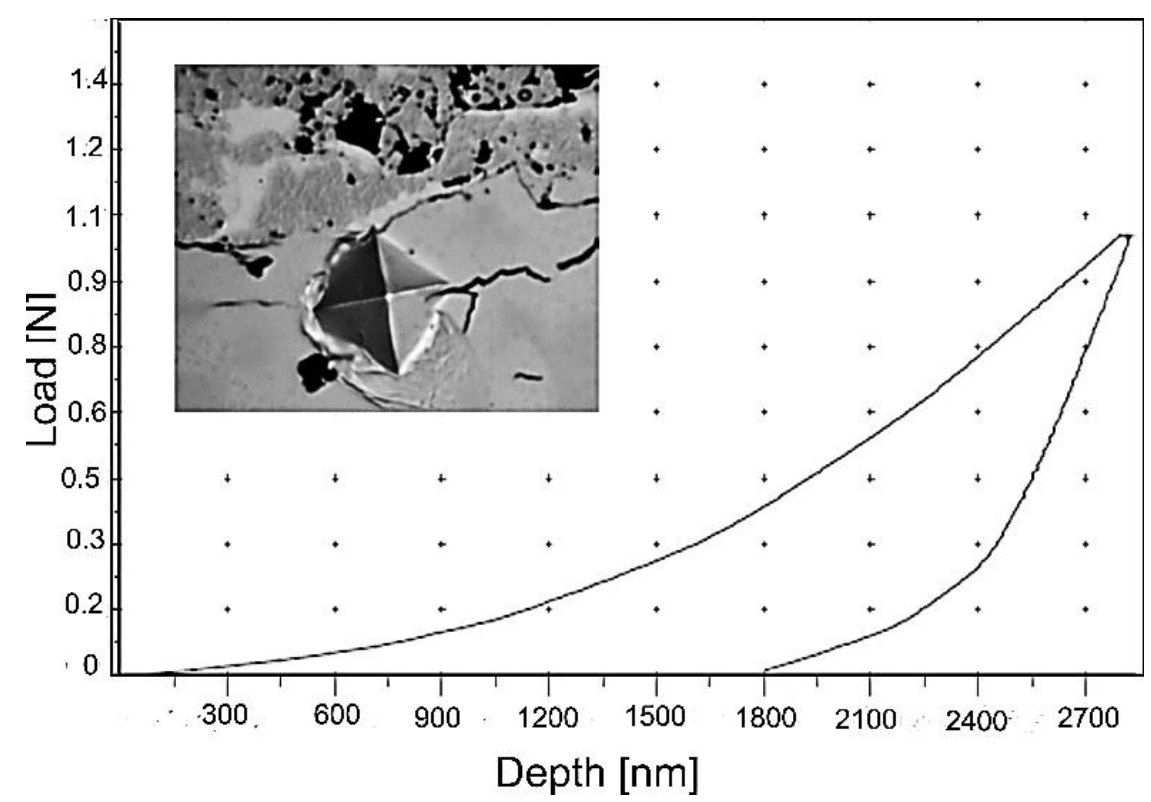

Fig. 3. Hysteresis curve of load-deformation in the system of WC-Co+Co/ductile cast iron obtained at $1 \mathrm{~N}$ load in the area of occurrence of Co particles $\left(\mathrm{H}_{\mathrm{IT}}=6.58 \mathrm{GPa}, \mathrm{E}_{\mathrm{IT}}=162.42 \mathrm{GPa}\right)$ 
Ring electron diffractions confirmed the nanocrystalline nature of the coating structure. In addition, based on fuzzy diffraction rings, its amorphous character can also be assumed. Thanks to the EDS (Energy Dispersive X-ray Spectroscopy) technique, a point analysis of the chemical composition in the coating was obtained and the elements constituting the coating $-\mathrm{W}$ and $\mathrm{Co}-$ were identified.

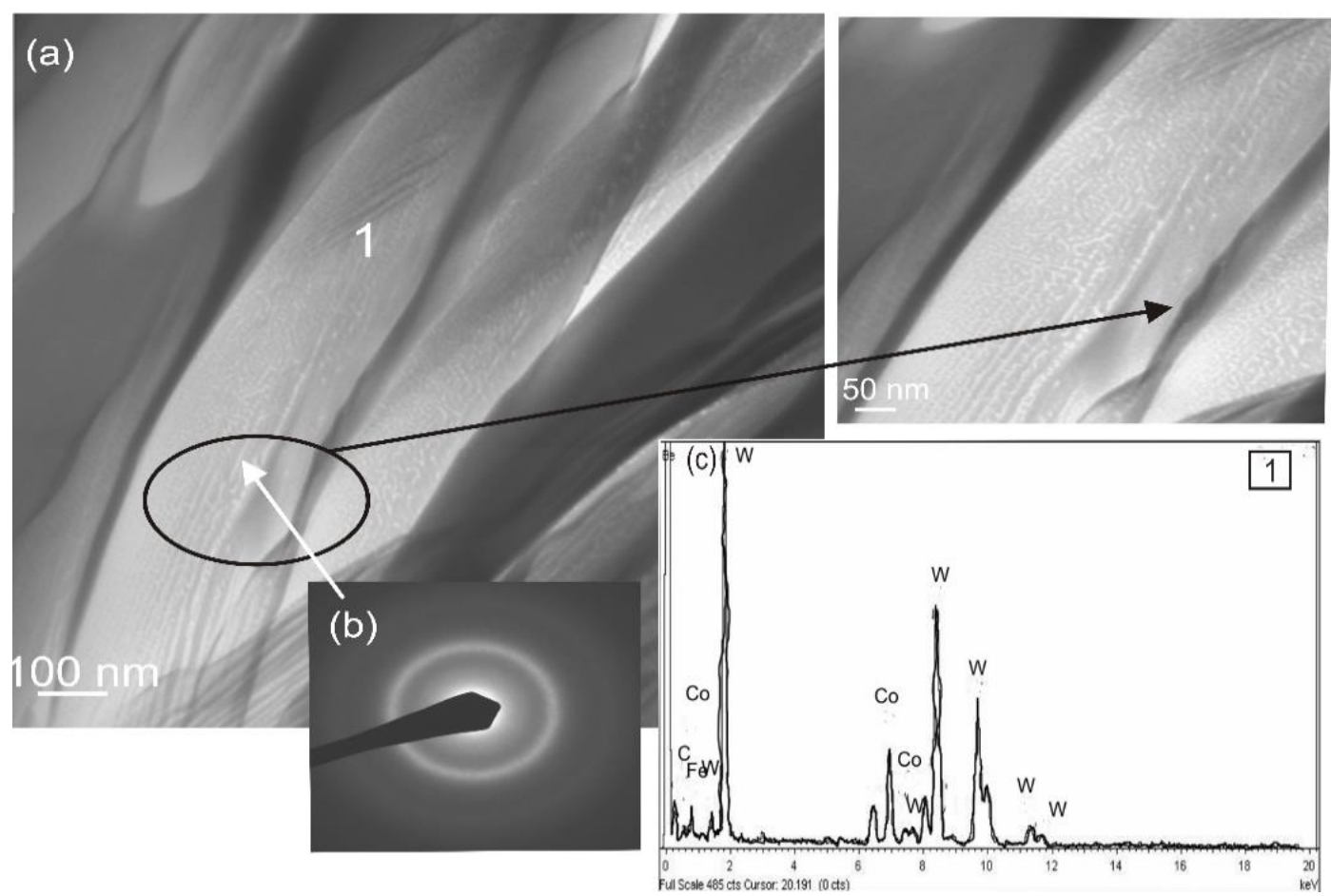

Fig. 4. a) TEM analysis of the composite coating (WC-Co+Co) deposited on ductile cast iron with corresponding c) EDS spectra and b) representative area diffraction pattern indicates the formation of nanocrystalline structure

WC decarburises to metallic $\mathrm{W}$ and leads to the formation of a phase limiting the amount of WC particles during spraying (carbides with a lower carbon content are formed). In addition, volume proportions and average crystallite sizes of individual phases in the tested coating were determined (Table IV). WC content amounted to $83.3 \mathrm{wt} . \%$ and the contents of $\mathrm{W}_{2} \mathrm{C}$ and $\mathrm{W}$ phases amounted to $5.4 \mathrm{wt} . \%$ and $3.3 \mathrm{wt} . \%$ respectively, while the content of Co amounted to $8.0 \mathrm{wt} . \%$. The volume proportion of WC in the structure of the composite coating is significant, which is related to the lower losses of WC during the coating spray process. It is worth mentioning that the values of the average crystallite sizes of the individual phases demonstrate the nanocrystalline nature of the coating. Figu-re 6 presents a comparison of bending test results for the WC-Co/ductile cast iron and WC-Co+Co/ductile cast iron systems in the relation bending stress-deflection value. The values of maximum bending stresses for the WC-Co/ductile cast iron and WC-Co+Co/ductile cast iron systems amount to $515 \mathrm{MPa} \pm 7$ and $544 \mathrm{MPa} \pm 10$ respectivelv.

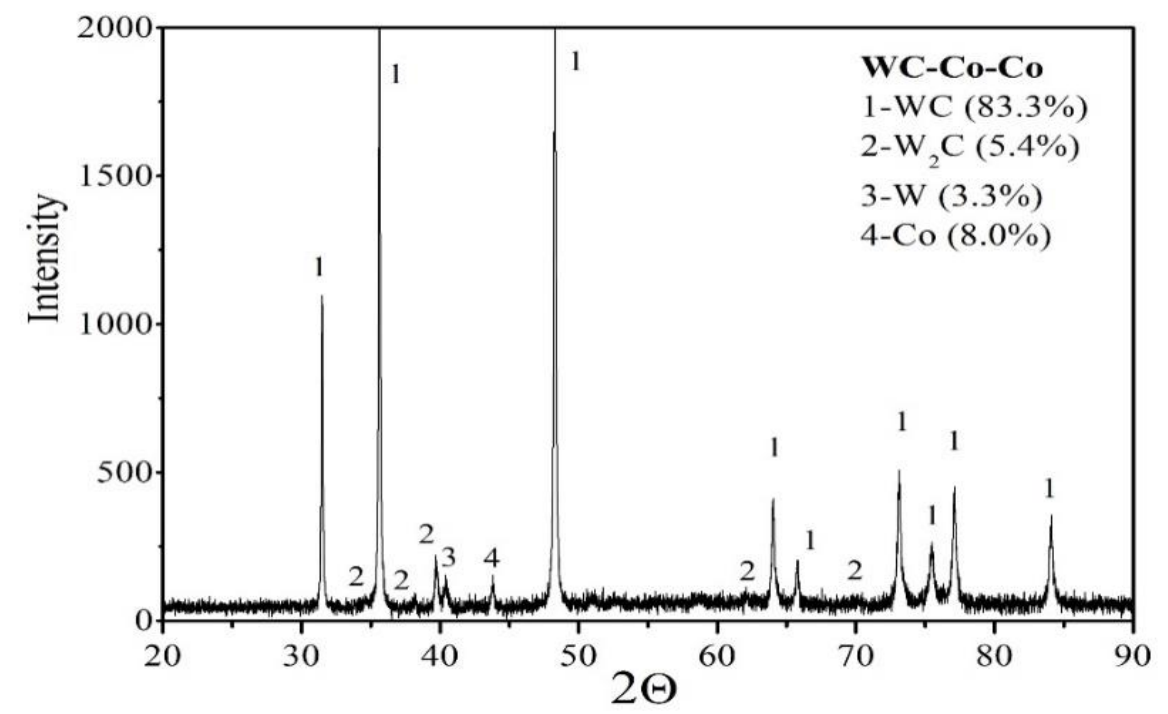

Fig. 5. X-ray diffraction pattern of the composite coating (WC-Co+Co) deposited on ductile cast iron by HVOF 
Table IV. Detailed results of XRD

\begin{tabular}{ccc}
\hline Composition & $\begin{array}{c}\text { Weight percentage of phase composition, } \\
\%\end{array}$ & $\begin{array}{c}\text { Crystal size from XRD DXRD, } \\
\text { nm }\end{array}$ \\
\hline WC & 83.3 & 50 \\
$\mathrm{~W}_{2} \mathrm{C}$ & 5.4 & 33 \\
$\mathrm{~W}$ & 3.3 & 26 \\
$\mathrm{Co}$ & 8.0 & 19 \\
\hline
\end{tabular}

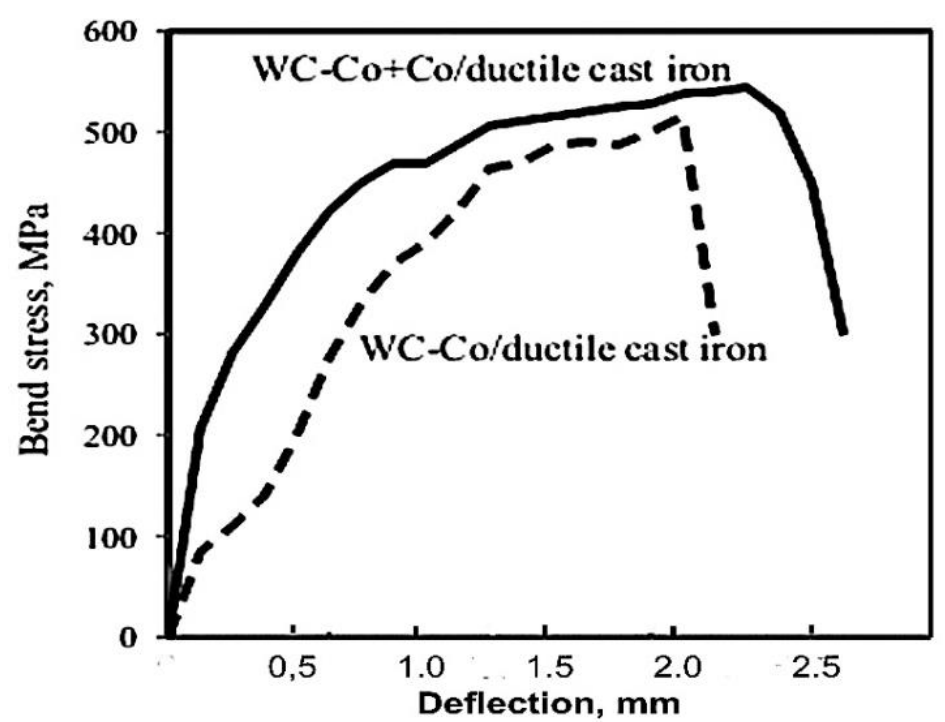

Fig. 6. Bend test curves recorded for the systems type: $\mathrm{WC}-\mathrm{Co}+\mathrm{Co} /$ ductile cast iron and WC-Co/ductile cast iron

In the tested systems, the bending curves are parabolic. The character of the stress-deflection curve for the WC-Co+Co/ductile cast iron system indicates that the mechanism of damage proceeds in a more typical way as for plastic materials, whereas for the WC-Co/ductile cast iron system it proceeds as for brittle materials.

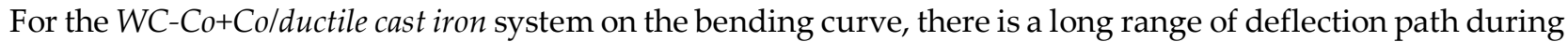
which the stress gently rises and then falls. The value of the deflection arrow followed by a drop in stress leading to the damage of the sample is approx. $2.2 \mathrm{~mm}$. However, there is no such a long range of deflection path for the WC-Co/ductile cast iron system. Comparing the curves obtained, it can be concluded that for the WC-Co/ductile cast iron system, there is a slight decrease in the strength parameters of the bending process, and the deflection arrow is reduced to the value of $1.8 \mathrm{~mm}$. It is worth noting that in the WC-Co/ductile cast iron system, the coating is harder and more brittle, which consequently limits the dissipation of plastic deflection energy, while the intensively increasing load causes crack propagation and a small deflection range. It should also be emphasized that an important factor influencing the reduction of the final strength of the coating system are internal stresses caused by differences in the values of linear and substrate expansion coefficients. For the material from which the substrate is made, the value of the linear expansion coefficient is approx. $13.2 \cdot 10^{-6} \mathrm{~K}^{-1}$, while for the WC-Co type coating, it is approx. 5.5 $10^{-}$ ${ }^{6} \mathrm{~K}^{-1}$ [8]. Due to the value of linear expansion coefficient $\mathrm{Co}\left(12 \cdot 10^{-6} \mathrm{~K}^{-1}\right)$, the coating material composition in the spraying process will not generate additional internal stresses, which consequently guarantees a permanent connection between the coating material and the substrate.

Observations of sample cracks after the bending test conducted on a scanning microscope (Fig. 7) indicate that in the WC-Co/ductile cast iron system, the damage occurs within both the coating near the coating/substrate interface and along the coating/substrate interface, while in WC-Co+Co/ductile iron destruction occurs only along the coating/substrate interface. Adhesion tests and determination of other symptoms of mechanical damage were carried out on the following systems: WC-Co/ductile cast iron and WC$\mathrm{Co}+\mathrm{Co} /$ ductile cast iron. Figure 8 shows the dependence of the depth of indenter penetration and the acoustic emission signal on the normal force and the path of the penetrator together with the image of cracks on the surfaces of the tested systems. 


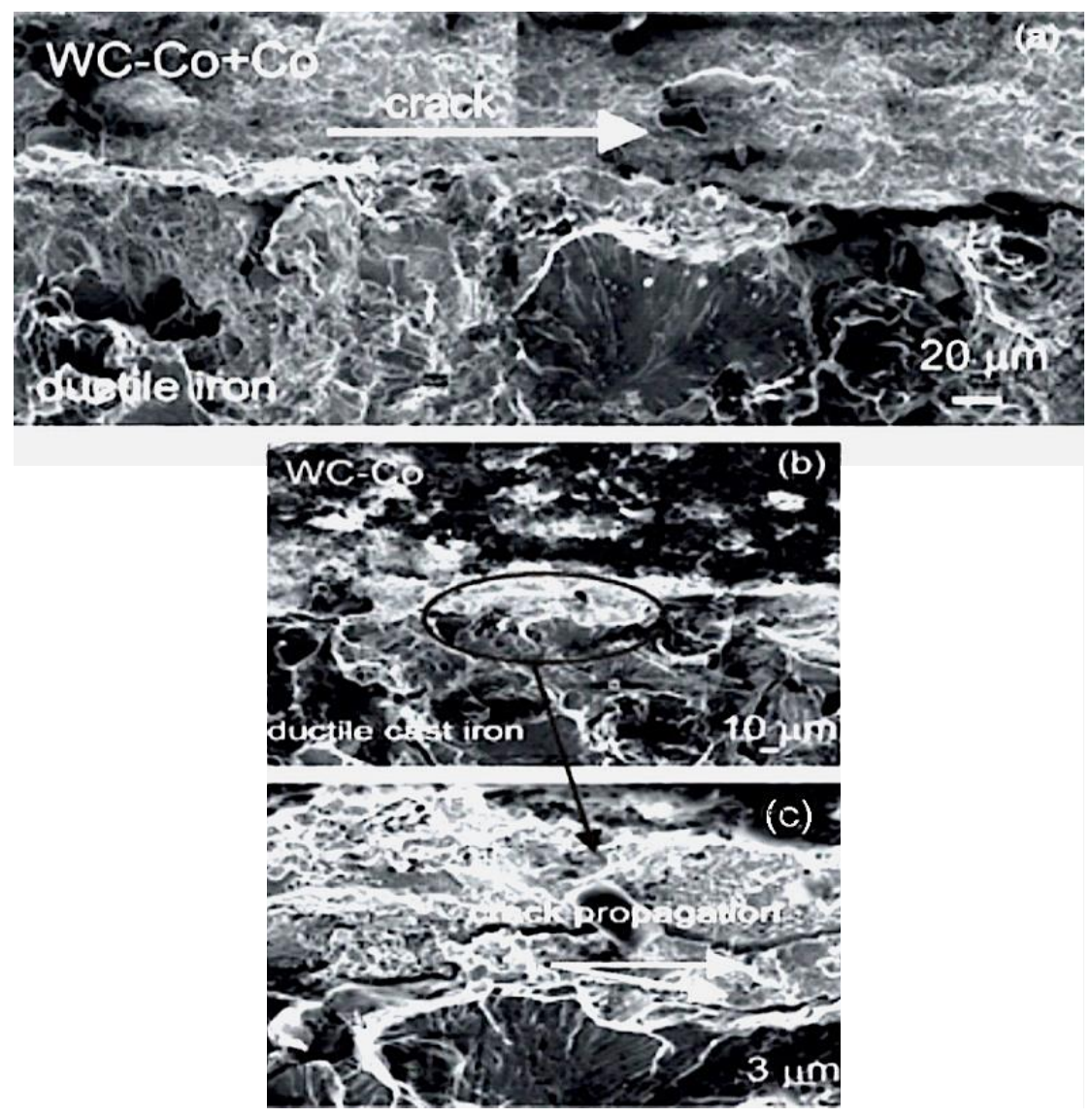

Fig. 7. SEM micrographs of the fracture surface after bend test in the systems: a) WC-Co+Co/ductile cast iron, b) WC-Co/ductile cast iron and c) magnified area selected in Fig. $7 \mathrm{~b}$

Damage to the coating/substrate system is detected and evaluated on the basis of direct microscopic observation of the crack formed and by measuring the acoustic emission. The normal force at which damage occurs is called the critical load Lc. It is worth noting that the critical load values were estimated at the large penetration depths of the indenter (after the fifth movement of the scratch test head along the same scratch trace). Table $\mathrm{V}$ presents the values of the critical load corresponding to the appearance of the first small cracks in the tested coatings and adhesive cracks as well as the maximum depths of the indenter's penetration. It is worth mentioning that the critical force as the measure of adhesion is the smallest normal force causing loss of adhesion of the coating with the substrate. Its value was assessed by recording the changes of acoustic emission signals and microscopic observations carried out with a light microscope forming an integral part of the platform. During the scratch test, no large cracks in the coatings were observed. Separation of fragments of layers related to subsurface zones, there was also no delamination of individual coating zones or the detachment of a given coating from the substrate. Initially, small cohesive cracks were observed at a load of $5.9 \mathrm{~N}$ for the composite coating (WC-Co+Co). A sharp increase in the acoustic emission value corresponds to the first chippings or the first cracks in the coating.

Table V. Scratch test results for layered systems

\begin{tabular}{ccccc}
\hline Coatings & \multicolumn{4}{c}{ Observed wear } \\
& LcI [N] & Layer cracks with large delamination areas \\
& $3.7 \pm 0.7$ & $11.5 \pm 0,4$ & Lc2 $_{\text {cI }}[\mu \mathrm{m}]$ & $\mathbf{h}_{\max }[\mu \mathrm{m}]$ \\
\hline WC-Co & $5.9 \pm 1.5$ & $23.0 \pm 0.6$ & $18 \pm 0.7$ & $16.2 \pm 0.4$ \\
WC-Co+Co & & $30 \pm 0.6$ \\
\hline
\end{tabular}

where: $\quad$ LCI - cohesive crack of the coating

Lc2 - adhesion crack in the scratch track

hCI - indenter penetration depth at LCI

$\mathrm{h}_{\max }-$ indenter penatration depth at max. loading $20 \mathrm{~N}$ 


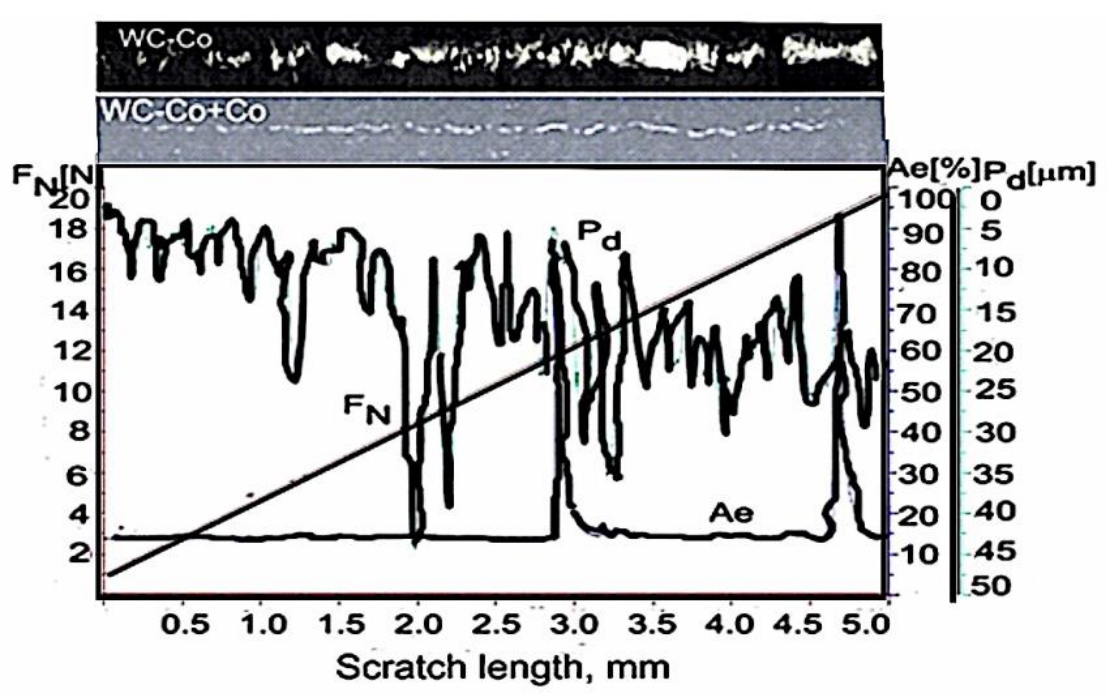

Fig. 8. Results of the WC-Co+Co/ductile cast iron system obtained from the scratch test for a present force of $1 \div 20 \mathrm{~N}$ with the line of surface scratching for the coatings: WC-Co and WC-Co+Co

The layer cracked on the edge of the scratch track at a load of $18 \mathrm{~N}$. The load value at which this form of wear appeared was considered a critical load of the layer Lc. This layer wear process indicates its very good adhesion to the substrate. Not observed for the composite coating (WC-Co+Co) unveiling of the substrate. In turn, for the WC-Co coating, a large crack with a roof shape was observed already at a load of $3.7 \mathrm{~N}$. The complete damage of the coating was observed at a load of $8.5 \mathrm{~N}$. The value of this load was assumed to be Lc. In turn, the indenter's penetration was lower for the WC-Co coating, which is associated with greater microhardness of this layer on the cross-section. In addition, increasing the plasticity and cohesion (lower porosity) of the WC-Co coating by introducing 10\% of Co particles to the coating material influences the reduction of wear. The scratch trace for the composite coating shows that cracks propagate in the areas of Co particles (the particles take over the propagation of cracks).

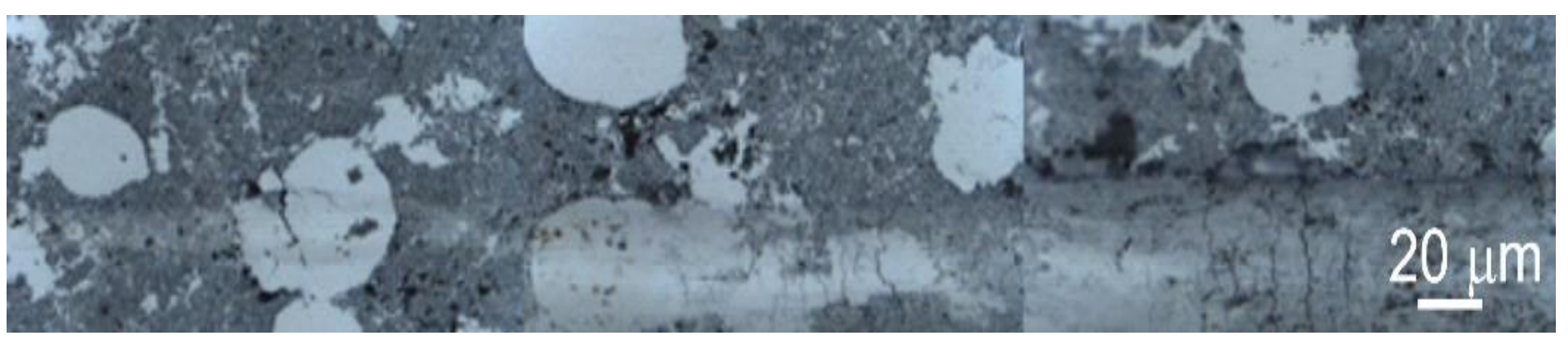

Fig. 9. LM images of a scratch track of WC-Co+Co coating deposited on ductile cast iron

Plastic Co particles distributed in the brittle and hard matrix of the coating cause the dissipation of the cracking energy at the braking and crack deflection distance (Fig.9). A significantly lower critical load value for the WC-Co coating compared to the $\mathrm{WC}-\mathrm{Co}+\mathrm{Co}$ composite coating indicates its greater brittleness. It is worth mentioning that the factors affecting the critical load value in the scratch test are, adhesion and cohesion of the coating/substrate system, hardness and roughness of the substrate, hardness and roughness of the coating, coating thickness and internal stresses occurring in the coating $[4,5,10]$.

\section{Conclusions}

The following conclusions were made on the basis of the tests and analysis of the results carried out:

The composite coating (WC-Co+Co) applied by means of the HVOF method on ductile cast iron is characterised by low porosity, compact structure, good adhesion to the substrate and high hardness. The coating structure contains partially melted Co particles as well as highly dispersed WC particles embedded in the cobalt matrix, reaching nanocrystalline dimensions.

The composite coating (WC-Co+Co) structure provides good resistance to cracking. The damage occurs along the coating/substrate interface. The cracks initiated in the coating - perpendicular to the substrate - do 
not violate the interface and do not break into the crack in the substrate material. In the composite coating, the increase in resistance to cracking occurs by inhibiting or deflecting the cracking in the Co particles distribution areas.

The composite coating (WC-Co+Co) on ductile cast iron has a good wear resistance related to the effect of plasticising the coating by doping the base ceramic powder with metallic particles. The reason for the increased wear resistance of composite coatings is the presence of Co particles in the coating structure, increasing their cohesion and the ability to transfer significant loads in the coating.

Acknowledgments: The present project was financially supported by AGH University of Science and Technology (The statutory contract no 11.11.180.958)

\section{References}

1. Picas J.A.; Xiong Y.; Fuste M.P.; Schoenung J.M. Microstructure and wear resistance of WC-Co by three consolidation processing techniques, Inter. J. Refractory Metals and Hard Materials 2009, vol. 27, 344-349. [CrossRef]

2. Wang H.B.; Song X.Y.; Liu X.M.; Gao Y.; Wei C.B.; Wang Y.; Guo G.S. Effect of carbon content of WC-Co composite powder on properties of cermet coating. Powder Technol 2013, vol. 246, 492-498. [CrossRef]

3. Kumar A.; Sharma A.; Goel S.K. Erosion behaviour of WC-10Co-4Cr coating on 23-8-N nitronic steel by HVOF thermal spraying. Appl. Surf. Sci. 2016, vol. 370, 418-426. [CrossRef]

4. Vashishtha N.; Khatirkar R.K.; Sapate S.G. Tribological behaviour of HVOF sprayed WC-12Co, WC-10Co-4Cr and Cr3C2-25NiCr coatings. Tribol. Inter 2017, vol. 105, 55-68. [CrossRef]

5. Chivavibul P.; Watanabe M.; Kuroda S.; Shinoda K. Effects of carbide size and Co content on the microstructure and mechanical properties of HVOF-sprayed WC-Co coatings, Surf. Coat. Technol. 2007, vol. 202, 509-521. [CrossRef]

6. Strecker A.; Salzberger U.; Mayer J. Specimen preparation for transmission electron microscopy: reliable method for cross-sections and brittle materials, Prakt. Metallogr. 1993, 30, 482-495. [Hyperlink]

7. PN-EN ISO 20502:2016 High quality ceramics (advanced ceramics, advanced technical ceramics) - Determination of the adhesion of ceramic coatings in the scratch test, in Polish

8. Berger L-M.; Ettmayer P.; Vuoristo P.; Mantyla T.; Kunert W. Microstructure and properties of WC- $10 \% \mathrm{Co}-4 \% \mathrm{Cr}$ spray powders and coatings. I Powder characterisation. J Therm. Spray Technol. 2001, Vol. 10, 311-325. [Hyperlink]

9. Bolelli G.; Berger L-M.; Bonetti M.; Lusvarghi L. Comparative study of the dry sliding wear behaviour of HVOFsprayed WC-(W,Cr)2C-Ni and WC-CoCr hardmetal coatings. Wear 2014, Vol. 309, 96-111. [CrossRef]

10. Azizpour M.J.; Norouzi S.; Mohammadi M.H. Mechanical properties of WC-12Co HVOF coatings. J. Amer. Sci. 2011, Vol. 7, 609-614. [CrossRef]

(C) 2019 by the authors. Submitted for possible open access publication under the terms and conditions of the Creative Commons Attribution (CC BY) license (http://creativecommons.org/licenses/by/4.0/). 